\title{
A POLÍTICA DE IMIGRAÇÃO DA UNIÃO EUROPEIA E AS QUESTÕES RELATIVAS AOS DIREITOS HUMANOS E AO MULTICULTURALISMO NO VELHO CONTINENTE
}

\author{
Mateus Dalmáz ${ }^{1}$ \\ Daniela Delarmelin ${ }^{2}$ \\ Eduardo Schmitz ${ }^{3}$ \\ Fernanda Cristina Wiebusch Sindelar ${ }^{4}$ \\ Sabrina Thais Petter ${ }^{5}$
}

\begin{abstract}
Resumo: Tendo em vista os milhares de imigrantes asiáticos e africanos que anualmente vêm atravessando o mar Mediterrâneo em direção à Europa, notadamente a partir de 2014, e considerando a existência, por um lado, de uma política de imigração formulada pela União Europeia (UE) e, por outro, de reaçóes autônomas por parte da sociedade civil dos países europeus em relação aos imigrantes, busca-se, nesta pesquisa, analisar a forma através da qual o organismo internacional europeu e as sociedades europeias tratam o multiculturalismo e os direitos humanos na regiáo. Para tanto, utiliza-se como objeto de estudo as formulaçóes previstas no Programa de Estocolmo e na Regulamentação de Dublin, documentos que definem a política de imigração da União Europeia, bem como artigos científicos que analisam a atuação da UE e as reaçôes sociais cotidianas à presença de imigrantes na Europa. Considera-se como hipótese que, apesar dos acordos de Estocolmo e Dublin preverem uma atitude multilateral da União Europeia no sentido de respeitar o multiculturalismo e os direitos humanos, de acordo com os preceitos defendidos pela Organização das Naçóes Unidas (ONU), há demonstraçóes xenófobas por parte da sociedade civil de alguns países do velho continente, como Alemanha, França, Grécia e Itália. Utiliza-se a corrente teórica construtivista, baseada em Barry Buzan, Oly Waever e Jaap de Wild (2008), para os quais as sociedades civis e as organizaçóes internacionais também se constituem em atores internacionais relevantes nas Relaçóes Internacionais, ao lado do Estado. Assim, formulaçóes em nível institucional (como o Programa de Estocolmo e de Dublin) e atitudes coercitivas societárias (como as de parcelas da população europeia)
\end{abstract}

1 Doutor em História, professor do curso de Relações Internacionais da Univates (Lajeado/RS).

2 Acadêmica do curso de Relações Internacionais da Univates (Lajeado/RS).

3 Acadêmico do curso de Relações Internacionais da Univates (Lajeado/RS).

4 Doutora em Economia, professora do curso de Relações Internacionais da Univates (Lajeado/RS).

5 Acadêmica do curso de Relações Internacionais da Univates (Lajeado/RS). 
se revelam condicionantes importantes do sistema internacional no que diz respeito às migraçóes ao multiculturalismo e aos direitos humanos. Conceitua-se o multiculturalismo conforme a perspectiva de Santos e Nunes (2003), para os quais o pluralismo cultural não necessariamente é harmônico. Caracteriza-se os Direitos Humanos conforme a definição da Declaração Universal dos Direitos Humanos (ONU, 2016), segundo a qual os direitos naturais clássicos identificados pela filosofia política contratualista (como o direito à vida, liberdade e propriedade) precisam ser assegurados pelo direito internacional, e aplica-se uma metodologia qualitativa proposta por Ciro Flamarion Cardoso e Ronaldo Vainfas (1997) para interpretação de textos, caracterizada por uma hermenêutica que realize uma contextualização histórica das fontes, relacionando texto e contexto. Deste modo a conjuntura histórica multipolar, marca das Relaçôes Internacionais após a Guerra fria, é ferramenta de análise essencial para a compreensáo do conteúdo dos artigos e documentos produzidos em torno das questóes relativas às imigraçóes via mar Mediterrâneo nos últimos anos.

Palavras-chave: Migraçóes. Direitos Humanos. Multiculturalismo. União Europeia.

\begin{abstract}
Given the thousands of asian and african immigrants who come each year across the Mediterranean into Europe, especially from 2014, and considering the existence, on the one hand, of an immigration policy formulated by the European Union (EU) and on the other, of autonomous reactions from civil society of european countries for immigrants looking to this research, analyze the way in which the european international organization and european societies treat multiculturalism and human rights in the region. Therefore, it is used as an object of study the formulations set out in the Estocolmo Program and in the Dublin Regulation, documents defining the European Union's immigration policy and scientific articles that analyze the EU's action and everyday social reactions to the presence of immigrants in Europe. It is considered as hypothesis that despite the Estocolmo and Dublin agreements Dublin to provide for a multilateral approach of the European Union to respect multiculturalism and human rights, in accordance with the principles defended by the United Nations (UN), there are xenophobic statements by civil society of some old world countries such as Germany, France, Greece and Italy. Used constructivist theoretical current based on Barry Buzan, Oly Waever and Jaap de Wild (2008), for which civil society and international organizations also are international actors relevant in international relations, alongside the State. Them, formulations institutional level (such as the Estocolmo and Dublin Programs) and corporate coercive attitudes (such as parts of the european population) are revealed important constraints of the international system with regard to migration to multiculturalism and human rights. Conceptualizes to multiculturalism as the prospect Santos and Nunes (2003), for which the pluralism of Western society admits different forms of reaction to the events. Characterized Human Rights as defined in the Universal Declaration of Human Rights (UN, 2016), according to which the classical natural rights identified by contractarian political philosophy (such as the right to life, liberty and property) must be secured by a right international (though here to question the perspective contractualist in International Relations), and apply a qualitative methodology proposed by Ciro Flamarion Cardoso and Ronaldo Vainfas (1997) for interpreting texts, characterized by a hermeneutics to conduct a historical contextualization of sources relating text and context, without the submission of one another. Them the multipolar historical conjuncture mark of International Relations after the Cold War, it is essential analytical tool for understanding the content of the articles and documents produced on issues related to immigration via the Mediterranean in recent years.
\end{abstract}

Keywords: Migrations. Human Rights. Multiculturalism. European Union. 


\section{Introduçáo}

Nas matérias a respeito de temas internacionais e nos estudos de especialistas da área tem sido frequente a abordagem do tema das imigrações de africanos e asiáticos para o continente europeu. Mais do que isso, as mídias interativas e de massa e os analistas de um modo geral vem destacando a disparidade entre as instituições oficiais e a sociedade europeia na forma de lidar com a questão: o discurso de acolhimento dos primeiros, a sensação de insegurança do segundo. Diante disso, considerando a relevância do assunto na discussão cotidiana e acadêmica, busca-se neste artigo analisar a forma através da qual a União Europeia (UE) e as sociedades europeias tratam o multiculturalismo e os direitos humanos na região a partir das migrações asiáticas e africanas através do mar Mediterrâneo, especialmente a partir de 2014.

Nos dois últimos anos, vem sendo cada vez maior o contingente de imigrantes da África e da Ásia para a Europa. Por razões conjunturais, como a instabilidade econômica e política, e estruturais, como infraestrutura precária e conflitos religiosos acirrados, parcelas das sociedades dos continentes banhados pelo mar Mediterrâneo enxergam na Europa a possibilidade de uma vida com liberdade de expressão e acesso ao mercado de trabalho. A partir de tal cenário, questionase: de que modo a União Europeia e a sociedade civil do velho continente vem lidando com os imigrantes provenientes da Ásia e da África nos últimos dois anos? Considera-se como hipótese que, apesar do Espaço Schengen (1995), do Programa de Estocolmo (2010) e da Regulamentação de Dublin (2013) preverem uma atitude multilateral da União Europeia no sentido de respeitar o multiculturalismo, a livrecirculação de pessoas e os direitos humanos, de acordo com os preceitos defendidos pela Organização das Nações Unidas (ONU), há demonstrações de intolerância por parte da sociedade civil de alguns países do velho continente, como Alemanha, França, Grécia e Itália. Isto é, percebe-se uma dualidade na forma através da qual a Europa vem lidando com a questão: de um lado, institucionalmente, via UE, há um discurso de tolerância cultural e acolhimento aos imigrantes; de outro, cotidianamente, na sociedade, há a reafirmação da identidade social e a insegurança quanto à liberdade individual e ao bem-estar social na região.

Para o desenvolvimento da análise, utiliza-se a corrente teórica construtivista, baseada em Barry Buzan, Oly Waever e Jaap de Wild (2008), para os quais as sociedades civis e as organizações internacionais também se constituem em atores internacionais relevantes nas Relações Internacionais, ao lado do Estado. Assim, formulações em nível institucional (como o acordo de Estocolmo e de Dublin) e atitudes coercitivas societárias (como as de parcelas da população europeia) se revelam condicionantes importantes do sistema internacional no que diz respeito às migrações ao multiculturalismo e aos direitos humanos.

A formulação teórica dos autores também diz respeito à segurança internacional, tema maior dentro do qual se inserem as políticas da UE para os imigrantes e o comportamento da sociedade civil europeia relativo à questão. Para eles, é possível lançar dois pontos de vista sobre segurança: uma visão ampla, que 
incorpore novos setores (economia, sociedade e ambiente) para compreender a formulação de uma política de segurança; e uma visão estreita, que valorize aspectos tradicionais (essencialmente militares e políticos). Concorda-se, neste artigo, com a importância de analisar novos setores em segurança internacional, cada um correspondente a tipos de interação entre Estado e sociedade civil, como, por exemplo, a interação de coerção na esfera militar; de autoridade na política; de produção, gestão e finanças na economia; de ativismo societário na ambiental e, em especial para este estudo, de identidade coletiva na esfera social. Em outras palavras, o referencial teórico proposto por Barry Buzan, Oly Waever e Jaap de Wild (2008) considera que a sociedade de uma região é um ator internacional relevante, tanto quanto um Estado ou organização supranacional. A compreensão de uma política de segurança internacional a partir do exame do setor social permite entender a interação entre o Estado e a sociedade civil a partir de valores e atitudes provenientes da sociedade, e não apenas das instituições oficiais, de modo que estas levam em consideração o comportamento daquela na definição de uma política de segurança. Do mesmo modo que cada setor, individualmente, pode tomar providências para minimizar uma sensação de insegurança diante de qualquer ameaça. Assim, neste artigo, considera-se que os acordos de Schengen (1995), Estocolmo (2010) e Dublin (2013) - por iniciativa da UE - e as reações xenófobas e politicamente radicais - por parte da sociedade europeia - constituemse em elementos importantes para a análise da política de segurança da região, em geral, e da forma através do qual os imigrantes vêm sendo tratados, em particular. Vale considerar que "a set of states whose major security perceptions and concerns are so interlinked that their national security problems cannot reasonably be analyzed or resolved apart from another" (BUZAN, WAEVER, WILD, 2008, p. 12), ou seja, o foco aqui dado à União Europeia (esfera política) e à sociedade civil (esfera social) não exclui outros setores (militar, econômico, ambiental) também relevantes na elaboração de uma política de segurança. Apenas amplia a análise para além da questão meramente política.

O estudo sobre a onda migratória para a Europa requer, ainda, o uso do conceito de multiculturalismo, o qual aqui é tratado não apenas como sendo a coexistência de formas culturais em sociedades globais, como também as diferenças e dificuldades de convivência entre culturas diferentes em contextos transnacionais. Afinal,

a expressão multiculturalismo designa, originalmente, a coexistência de formas culturais ou de grupos caracterizados por culturas diferentes no seio de sociedades "modernas". Rapidamente, contudo, o termo se tornou um modo de descrever as diferenças culturais num contexto transnacional e global. O termo apresenta as mesmas dificuldades e potencialidades do conceito de "cultura", um conceito central das humanidades e das ciências sociais e que, nas últimas décadas, se tornou um terreno explícito de lutas políticas (SANTOS; NUNES, 2003).

Vale esclarecer que, nesta pesquisa, aplica-se uma metodologia qualitativa proposta por Ciro Flamarion Cardoso e Ronaldo Vainfas (1997) para interpretação 
de textos, caracterizada por uma hermenêutica que realize uma contextualização histórica das fontes, relacionando texto e contexto, sem a submissão de um pelo outro. Deste modo, a conjuntura histórica multipolar, marca das Relações Internacionais após a Guerra fria, é ferramenta de análise essencial para a compreensão do conteúdo dos artigos e documentos produzidos em torno das questões relativas às imigrações via mar Mediterrâneo nos últimos anos.

O artigo está organizado em duas partes, além desta introdução e das considerações finais: a primeira trata da forma como a UE vem tratando as imigrações para o continente, em especial os acordos de Schengen, Estocolmo, Dublin e Turquia; e a segunda se refere à reação da sociedade civil europeia ao tema, como a xenofobia (islamofobia), o radicalismo político (populismo de direita), a identidade europeia (multiculturalismo) e as ameaças econômicas (bem-estar social) e de segurança (terrorismo, atentados, estupros).

\section{A Uniáo Europeia e as imigraçóes}

O Tratado de Lisboa, assinado em 2007, teve como objetivo reformar a estrutura da União Europeia para absorver mais países membros, democratizar a organização e convergir a política interna e externa do bloco (EUR-LEZ, 2016). Dado os novos desafios estruturais enfrentados pela União Europeia, como a instabilidade econômica e entrada de imigrantes, foi necessária a criação de um novo conjunto de diretrizes, surgindo assim o Protocolo de Estocolmo, que vigorou entre 2010 e 2014. O protocolo estabelece o que é mais relevante para UE no que se refere ao espaço de justiça, liberdade e segurança. Outro ponto chave neste protocolo foi estabelecer maior cooperação nas decisões coletivas dos 28 membros da UE (EUR-LEX, 2016).

Em 2013, foi desenvolvido o Regulamento de Dublin, que trata do processo que deve ser tomado no que se refere a pedidos de asilo nos países que fazem parte do espaço Schengen, um acordo de livre circulação de pessoas envolvendo trinta países europeus. Criado em 1995 com o intuito de integrar ainda mais a Europa e facilitar a circulação de pessoas para trabalhar ou viajar, o espaço também visava melhorar a mobilidade de mercadorias e serviços para facilitar o comércio na região. Entretanto, para que este espaço funcione de fato, os países signatários deveriam abrir mão de uma parte de sua soberania, principalmente no que se diz respeito ao controle de fronteiras (UNIÃO EUROPEIA, 2011).

Pode-se notar que o Espaço Schengen não se mostra eficaz no que se refere a lidar com o desafio dos refugiados, principalmente quanto à fragilidade de suas fronteiras externas, que não tiveram muita eficiência em deter o fluxo maciço de refugiados. A falta de eficácia do espaço Schengen para lidar com as migrações permitiu aos refugiados que entraram na fronteira liberdade para ir a qualquer país pertencente a este acordo. Com a falta de coordenação conjunta e de medidas eficazes, os países membros começaram a tomar decisões unilaterais e deram início à construção de barreiras físicas como, por exemplo, cercas e muros, dentro do Espaço Shengen, para impedir a entrada de refugiados nos seus países (LEHNE, 
2016). Outras medidas foram pensadas, segundo a agência de notícias Reuters, como a da Holanda, que criou um "mini-Shengen" para que se pudesse estabelecer maior coordenação para lidar com o problema dos refugiados, mas nada foi aprovado e o plano continua apenas como proposta (REUTERS, 2015).

O regulamento estabelece que o asilo seja responsabilidade do primeiro país em que o imigrante ou refugiado entrou. Mas, no decorrer da crise dos refugiados, que teve inicio em 2014, percebe-se uma enorme fragilidade no que se refere a este regulamento, pois muitos países, como Itália e Grécia, não conseguiram dar conta de suas obrigações conforme o protocolo, tanto por deficiências na infraestrutura quanto por reações avessas aos estrangeiros por parte da sociedade civil. A consequência disso é um enorme fluxo e de refugiados e muitos requerimentos de asilo para outros países como Alemanha e Áustria. A partir disso, começa a ficar clara a falta de cooperação entre os países da União Europeia e a demora para tomar alguma atitude perante o desafio de receber os imigrantes (LEHNE, 2016).

Ao longo da crise dos refugiados, fica clara a dificuldade na tomada de decisões conjuntas pela UE. Embora os Estados estivessem dispostos a abrir mão de parte de sua soberania para que se tornasse possível a resolução da crise econômica de $2008^{6}$ - que ainda não o foi - e a recuperação da economia, é perceptível que os mesmos não estão dispostos a o fazer para ajudar a solucionar a crise dos refugiados (LEHNE, 2016).

Em 2016, os 28 Estados-membros da União Europeia chegaram, finalmente, a um consenso sobre o que fazer a respeito da situação dos imigrantes. Este se dá através do acordo feito entre União Europeia e a Turquia, que foi assinado em março de 2016 e que prevê que todo refugiado que cruzar a fronteira com a Grécia, ou por outras partes da Europa, seja enviado para Turquia de modo que este país absorva parte dos imigrantes, os quais deverão ser selecionados pela UE em nome da segurança do bloco contra a possível entrada de terroristas. Os demais, neste caso, deverão ser deportados. Além do mais, a UE conta com um fundo inicial de $€ 3$ bilhões para ajudar a Turquia com os refugiados e também um complemento de $€ 3$ bilhões até 2018. Outra parte do acordo prevê que a Turquia deve tomar medidas marítimas e terrestres para evitar novas rotas de refugiados, além de, em parceria com a UE, enviar ajuda humanitária para a guerra na Síria (UE, 2016).

Pode-se considerar que o acordo é uma forma que a Europa encontrou de diminuir sua responsabilidade sobre a crise. Cabe salientar que as dificuldades com os imigrantes lidam para entrar na Europa e se inserir na região tem a ver com um aumento dos nacionalismos no velho continente nos últimos anos, algo que depõe contra o espírito de integração e convergência de políticas da UE:

A resposta da União Européia à crise dos refugiados foi enraizada em fatores estruturais profundas. Um elemento importante é a tensão entre a agenda

6 Convém esclarecer que a crise econômica de 2008 iniciou nos EUA e foi provocada pelas especulações imobiliárias que culminaram com a quebra de instituições bancárias e com a retração de crédito em nível global decorrente disso. 
de liberalização impulsionada pela economia da UE e a nacionalização em curso da política européia. Migração passa a ser um dos principais campos de batalha onde essas diferentes concepções de organização da vida em confronto Europa (LEHNE, 2016, p. 1).

Uma vez feita a análise da atuação da União Europeia diante dos imigrantes, parte-se para o exame da forma através da qual a sociedade europeia tem lidado com a questão. Conforme mencionado no início, os aspectos sociais são aqui tratados como a mesma relevância dos temas políticos para a compreensão do objetivo geral deste artigo.

\section{A sociedade europeia e as imigraçóes}

De acordo com a visão realista das Relações Internacionais, os estudos de segurança internacional são limitados às ameaças diretas à sobrevivência de um Estado e devem focar apenas nos atores que se utilizam da violência para alcançar objetivos políticos (DANNREUTHER, 2007). Entretanto, esta visão pode ser rejeitada, visto que problemas relacionados a outras áreas - como a econômica, social, ambiental e de saúde - podem ser tão relevantes quanto a primeira para a compreensão de uma determinada condição, portanto, a definição de segurança deve ser estendida com uma interpretação que abranja uma grande variedade de ameaças ao ser humano (HOUGH, 2009).

No caso da Europa, a imigração tem sido vista como um fator gerador de insegurança, uma vez que é relacionada a ameaças à integridade nacional e social e o aumento no número de movimentos e grupos xenófobos no continente, especialmente após os ataques realizados ao Charlie Hebdo e a Paris, no ano de 2015, e após os ataques realizados em Bruxelas, em março de 2016. Deste modo, quanto mais a União Europeia tem se sente exposta às ameaças à segurança, novos mecanismos de defesa e controle são criados, como, por exemplo, a Agenda Europeia para a Segurança para o período de 2015-2020, que visa apoiar a cooperação entre os Estados-membros em resposta às ameaças à segurança e incentivar os esforços comuns na luta contra o terrorismo, a criminalidade organizada e a cibercriminalidade, pois, embora a responsabilidade pela garantia da segurança interna seja uma competência dos Estados, os desafios transnacionais ultrapassam a capacidade de atuação individual de cada Estado e, portanto, exigem maior apoio da União Europeia nos esforços para reforçar a confiança e facilitar a cooperação, o intercâmbio de informações e uma ação conjunta (European Comission, 2015).

Entretanto, embora estas medidas tenham sido adotadas, o sentimento de insegurança compartilhado entre a sociedade dos países que compõem o bloco não diminui com a chegada de cada vez mais imigrantes ao continente. A população não se sente ameaçada apenas pelos ataques terroristas, mas também vê perigo na identidade da comunidade muçulmana que se opõe a diversos costumes ocidentais e na ideia de que os migrantes buscam instituir no continente suas práticas e a sharia - lei islâmica baseada no Corão (CRISTALDO, 2012); no aumento da fragilidade 
do sistema de bem-estar social, uma vez que este serve como um forte atrativo a migrantes que são vistos por parcelas da população como um indivíduo que apenas busca se aproveitar do sistema de assistência que não é capaz de se manter funcionando em consequência ao aumento no número de pessoas que recebem benefícios (SINN, texto digital, 2016); e no aumento da criminalidade interna, como a série de agressões sexuais, assaltos e assédios que segundo a BBC ocorreram na noite de 31 de dezembro de 2015 em Colônia na Alemanha e que teriam sido uma ação coordenada por mil homens que não falavam inglês ou alemão e, portanto, foram tomados como imigrantes.

De acordo com Pries e Bekassow (2015), a União Europeia, frente à crise migratória, tem adotado diversas diretrizes relacionadas à não-discriminação e ao respeito ao multiculturalismo, que abordam assuntos relativos à discriminação em suas diversas faces, como a crença religiosa, origem étnica, racial, orientação sexual, língua, opinião política, entre outros, e que deveriam constituir uma referência legal na esfera do bloco e de seus estados membros:

O percurso histórico, político e institucional de conformação da União Europeia, por si só, já evidencia condicionantes e intervenientes de toda ordem, em destaque, os aspectos étnicos, culturais, religiosos característicos e inescusáveis, dada toda diversidade europeia. No caso da União Europeia ficam marcantes todas as conquistas, mas também os entraves graduais, superados, ou ainda não, sobretudo em função de divergências inseridas na pluralidade de nações e diversidade multicultural na Europa (SANTOS, SANTOS, 2012, p.11-12).

Embora a UE possua esses mecanismos que preveem uma atitude de respeito às diferentes culturas e a não-discriminação, a realidade social se apresenta de outra forma, pois a sociedade civil vê na imigração um risco à identidade cultural europeia, que pode ser ilustrada pela ascensão dos partidos de extrema direita (KICINGER, 2004). Com a crescente onda imigratória, principalmente advinda dos países muçulmanos, aumentou o número e a popularidade dos partidos de extrema direita (nacionalistas) que pregam o anti-islâmismo, argumentando que a "cultura muçulmana" é incompatível com a "cultura europeia" (ZUQUETE, 2011). Os partidos políticos de extrema direita, embora compartilhem a hostilidade xenófoba em relação a praticamente todos os imigrantes e minorias, incentivam principalmente os movimentos anti-islã e muitas vezes se concentram fortemente em enquadrar o Islã como uma ameaça para os recursos, segurança e sobrevivência dos Estados europeus (GOODWIN; CUTTS; JANTA-LIPINSKI, 2014).

Preconceito cultural, xenofobia e nacionalismo parecem fazer parte, assim, de uma conjuntura desfavorável ao conjunto de acordos proposto pela UE - favorável ao multiculturalismo - no que diz respeito ao tratamento a ser dado aos imigrantes:

Este confuso contexto europeu tem demonstrado situações incomuns que vão desde movimentos que reforçam as desigualdades com regimes rígidos de controle de fronteiras para se evitar migrações, em certa medida, mostrando certo preconceito cultural velado, como situações mais explícitas de xenofobia, 
até mesmo com uso de força, a pretexto de proteção da população local, com certo discurso nacionalista (SOUZA, SANTOS, 2012, p.13)

Conforme assinala Zuquete (2011), a percepção da "ameaça" do Islamismo e a visão de uma Europa muçulmana se tornaram temas centrais na ideologia da extrema-direita europeia. Para eles, o Islamismo fere a ideia de uma "Europa cristã", colocando sob ameaça a cultura ocidental, enfraquecida e insegura por causa do contínuo fluxo migratório de populações muçulmanas. Tendo em vista que a Europa sofre com a diminuição populacional, a ênfase colocada no movimento anti-islã vem do medo e da luta contra a "islamização da Europa" e da necessidade de defesa das suas tradições. Os muçulmanos são caracterizados como o grupo mais vulnerável à discriminação de ordem religiosa em praticamente todos os estados membros da UE e, de acordo com Pries e Bekasson (2015), os assassinatos ocorridos na sede da revista Charlie Hebdo e no supermercado Hyper Cacher, em janeiro de 2015, aumentaram ainda mais os surtos de islamofobia em muitos países europeus, dando maior legitimidade aos movimentos de extremistas, como é o caso do movimento PEGIDA (Europeus Patriotas contra a Islamização do Ocidente) que, de acordo com a BBC, é um movimento político que teve início na Alemanha e tem protestado contra o islamismo e sua crescente influência na Europa. O grupo afirma estar preocupado com o aumento da imigração, embora seja contrário ao radicalismo e à disseminação de ódio, apelando para uma aplicação mais rigorosa das leis atuais da Alemanha em matéria de asilo e deportação. Esses movimentos têm crescido e se disseminado por vários países europeus. $\mathrm{Na}$ essência dos partidos políticos descritos como de extrema direita, o nacionalismo ainda é a força predominante. Mas, percebe-se a necessidade desses mesmos partidos de se apresentarem como representantes e defensores de uma comunidade europeia ocidental, unida por uma fé e valores cristãos comuns e contra "dominação" muçulmana (ZUQUETE, 2011).

Exemplo disso é que,

durante as eleições parlamentares austríacas de 2006, por exemplo, o Partido
da Liberdade fez campanha recorrendo a uma plataforma especificamente
anti-islâmica. Num dos seus cartazes eleitorais podia ver-se a catedral de
Viena com uma lua crescente em vez da cruz, e com uma legenda em que se
lia "este é o verdadeiro desejo oculto dos muçulmanos". Entre avisos contra
a iminente islamização do país, o partido flamengo Vlaams Belang assume-se
como o verdadeiro guardião do Cristianismo (ZUQUETE, 2011, p. 657).

Em um estudo realizado por Goodwin, Cutts e Janta-Lipinski (2014) sobre um partido radical islamofóbico denominado English Defence League (EDL) que se apresentava como uma organização de direitos humanos cujo objetivo era defender os direitos dos indivíduos de protestar contra a "invasão" do Islã na vida dos nãomuçulmanos, apontou que "os cidadãos que apoiam o movimento social anti-Islam tendem a ser homens mais velhos, com baixos níveis de educação, trabalhadores qualificados, que leem jornais de direita sensacionalistas e que apoiam partidos de direita nas eleições.” (GOODWIN, CUTTS, JANTA-LIPINSKI, 2014, p. 6). 
Esses cidadãos, conforme assinala Goodwin, Cutts e Janta-Lipinski (2014), percebem a imigração e minorias étnicas como tendo um impacto negativo na sociedade e antecipam futuros conflitos, sendo mais propensos a encontrar os movimentos anti-islã e a desenvolver atitudes como o preconceito racial, a hostilidade xenófoba e buscar a violência como resposta para esses imigrantes. Essas características apontam que os indivíduos se sentem ameaçados com a imigração e o multiculturalismo, e acabam por desenvolver mecanismos para reforçar sua posição contra a "ameaça" de mudanças nas suas relações intergrupais.

Por mais que a UE tente adotar medidas que preservem o multiculturalismo, a presença de indivíduos que possuem culturas muito diversas em um mesmo Estado traz consigo a formação de minorias (étnicas, religiosas, linguísticas) que muitas vezes não são aceitas pela população majoritária. Quando esse cenário é levado para o nível supranacional, como é o caso da UE, as dificuldades são ainda maiores, visto que a aproximação desses diferentes povos nem sempre ocorre de forma pacífica (LIMA, 2010). É o que salienta Zuquete (2011, p. 670):

Modelos de integração muçulmana — desde os multiculturais (no Reino Unido e nos Países Baixos) aos centralizados na assimilação (tal como acontece em França) - têm sido postos em causa e reprovados devido à realidade inevitável do aumento crescente de comunidades separadas que não se integram, e que muitas vezes se recusam a fazê-lo, chegando a mostrar-se manifestamente hostis às normas e valores da sociedade mais alargada.

Segundo Lima (2010, p. 5), “a União Europeia procura, assim, adotar medidas dirigidas à preservação dos direitos fundamentais, dos valores democráticos e a uma maior aproximação dos povos". Embora a convivência intrabloco se dê de forma menos conflituosa, a questão da imigração ainda é um tabu enfrentado pelo processo de integração, já que a UE não possui uma política comum sobre a questão da imigração, e muitos países tem fechado suas fronteiras para os imigrantes, colocando em perigo a livre circulação no espaço da União Europeia.

Conforme assinala Lima (2010, p. 6), "a convivência dentro de uma sociedade pluralista e democrática pressupõe não a renúncia ou substituição de valores culturais, mas a tolerância e o respeito com outros valores e outras culturas". Entretanto, apesar de boa parte da população europeia acreditar que o aspecto multicultural seja bom para a sociedade, ainda ocorrem muitos conflitos de razão étnica cultural, o que é atualmente um grande desafio para a integração da UE.

\section{Consideraçóes finais}

Diante da problematização a respeito da forma através da qual a União Europeia e a sociedade do velho continente vêm lidando com os imigrantes africanos e asiáticos desde 2014, sustentou-se a hipótese de que há, por parte do organismo internacional, a ênfase no respeito ao multiculturalismo e aos direitos humanos, e, por parte da sociedade, o sentimento de aversão ao estrangeiro e de insegurança. A divergência entre ambos parece se atenuar na medida em que o tratado com a Turquia é efetivado e o objetivo da UE com aquele país - basicamente 
o de fazer uma "triagem" - ficam expostos. Afinal, se a Turquia tem servido como uma espécie de anteparo organizado pela UE, parece que o receio da sociedade atingiu a cúpula da organização supraestatal.

As dificuldades do bloco para homogeneizar o tratamento aos imigrantes também podem ser atribuídas aos problemas históricos e estruturais da própria da UE, a qual convive com a instabilidade econômica e política de seus membros e com a supremacia do interesse nacional diante da cooperação multilateral. Convém lembrar que, antes mesmo das imigrações dos últimos dois anos, a União Europeia vinha enfrentando dificuldades de consenso para a implantação do Euro e para a adoção de medidas austeras nas econômicas nacionais.

As distinções culturais entre o ocidente e o oriente também tem um histórico anterior às imigrações dos últimos anos. Há séculos, o mundo ocidental moldou sua cultura em torno do pensamento racional, dos valores cristãos, da economia capitalista e da política fundamentada no liberalismo. E durante o mesmo período houve um estranhamento com um oriente inserido no mundo capitalista, porém, mais espiritual do que racional, politeísta e não-cristão, e signatário de um contrato social não emancipado da religião. Tais contrastes afloram no momento em que o fluxo migratório para a Europa viabiliza maiores contatos, situação em que o multiculturalismo alcança nitidez menos pela coexistência do que pela afirmação das diferenças. As ameaças de segurança provocadas pelos atentados e pela violência cotidiana, somadas às ameaças econômicas provocadas pela concorrência no mercado de trabalho e pelo rebaixamento do nível salarial podem ser a resposta para a pergunta sobre o novo fôlego da xenofobia, da islamofobia, da reafirmação da identidade europeia e pelo radicalismo político de direita que paira sobre a Europa.

\section{REFERÊNCIAS}

BBC. Ataques sexuais em série no Réveillon geram medo e revolta na Alemanha. 2016. Disponível em: < http://www.bbc.com/portuguese/noticias/2016/01/160105_abuso_ sexual_ano_novo_alemanha_rb>. Acesso em 19 de jun. de 2016.

BBC. Why are thousands of Germans protesting and who are Pegida? Disponível em: $<$ http://www.bbc.co.uk/newsbeat/article/30694252/why-are-thousands-of-germansprotesting-and-who-are-pegida> Acesso em: 17/06/2016

BUZAN, Berry, WAEVER, Oly, WILDE, Jaap de. Security: a new famework for analysis. London: Lynne Rienner Publisher, 2008.

CARDOSO, Ciro Flamarion S.; VAINFAS, Ronaldo (Orgs). Domínios da história: ensaios de teoria e metodologia. Rio de Janeiro: Campus, 1997.

UNIÃO EUROPEIA. A Comissão Europeia adota medidas para reforçar a cooperação da UE na luta contra o terrorismo, a criminalidade organizada e a cibercriminalidade. Estrasburgo: 2015. Disponível em: <http://europa.eu/rapid/press-release_IP-15-4865_ pt.htm>. Acesso 15 de jun. de 2016. 
UNIÃO EUROPEIA. Segurança: UE reforça resposta às ameaças híbridas. Bruxelas, 2016. Disponível em: <europa.eu/rapid/press-release_IP-16-1227_pt.pdf>. Acesso 09 de jun. de 2016.

CRISTALDO, Janer. A morte da Europa que amo. São Paulo, 2012. Disponível em: <http://www1.folha.uol.com.br/fsp/opiniao/68311-a-morte-da-europa-que-amo. shtml>. Acesso em 19 de jun. de 2016.

DANNREUTHER, Roland. International Security: the contemporary agenda. Cambridge: Polity Press, 2007.

GOODWIN, Matthew J. CUTTS, David. JANTA-LIPINSKI, Laurence. Economic Losers, Protestors, or Xenophobes? Predicting Public Support for a Counter-Jihad Movement. Political Studies Association, 2014. Disponível em: <http://web.a.ebscohost. com/ehost/pdfviewer/pdfviewer?sid=4d445ef5-7c0f-488a-a8ff-ef3df4b6b2ad\%40sessio nmgr4004\&vid=1\&hid=4206> Acesso em: 05/06/2016

HOUGH, Peter. Understanding Global Security. 2a . edição. Nova York: Routledge, 2009.

CARMEGIEEUROPE. Disponível em: < http://carnegieeurope.eu/2016/04/21/ tempting-trap-of-fortress-europe/ixdx> Acesso em: 21 abril 2016.

CARMEGIEEUROPE. Disponível em: <http://carnegieeurope.eu/ strategiceurope $/$ fa $=62280>$ Acesso em: 15 maio 2016.

CARMEGIEEUROPE. Disponível em: < http:/ / carnegieeurope.eu/2016/02/04/howrefugee-crisis-will-reshape-eu/itj7> Acesso em 04 fevereiro 2016

KICINGER, Anna. International migration as a non-traditional security threat and the EU responses to this phenomenon. Central European Forum for Migration Research, 2004. Disponível em: <www.cefmr.pan.pl/docs/cefmr_wp_2004-02.pdf> Acesso em: 05/06/2016

LIMA, Sarah D. L. M. União Europeia e Multiculturalismo: a construção de uma nova realidade mundial. Anais do XIX Encontro Nacional do CONPEDI, 2010. Disponível em: <www.publicadireito.com.br/conpedi/manaus/arquivos/anais/fortaleza/3113.pdf> Acesso em: 05/06/2016

OSHIMA, Flávia Yuri. Terrorismo o teto de vidro da Europa. 2016. Disponível em: <http:/ / epoca.globo.com/tempo/noticia/2016/03/terrorismo-o-teto-de-vidro-daeuropa.html>. Acesso em 15 de jun. de 2016.

PRIES, Ludger. BEKASSOW, Natalia. Discriminação e Racismo na União Europeia: diagnóstico de uma ameaça negligenciada e da investigação científica correspondente. Sociologias, Porto Alegre, 2015. Disponível em: <http://www.scielo.br/scielo. php?script $=$ sci_arttext\&pid=S1517-45222015000300176\&lang=pt $>$ Acesso em: 09/06/2016

SINN, Hans-Weirner. Imigração e o Estado de bem-estar social. 2016. Disponível em: $<$ http:/ /internacional.estadao.com.br/noticias/geral,imigracao-e-estado-de-bem-estarsocial,10000013952>. Acesso 18 de jun. de 2016. 
SOUZA, Mércia C. SANTOS, Bráulio M. A União Europeia e sua perspectiva multiculturalista: reafirmação de respeito aos direitos humanos. Ágoras, 2012. Disponível em: <http://www.agoras.ufc.br/index.php/agoras/article/view/12> Acesso em: 09/06/2016.ZUQUETE, José P. Novos tempos, novos ventos? A extrema-direita europeia e o Islão. Análise social, 2011. Disponível em: <http://www.scielo.gpeari.mctes. pt $/$ scielo.php?script $=$ sci_arttext\&pid $=$ S0003-25732011000400003\&lang $=$ pt $>$ Acesso em: 09/06/2016.

SOUZA SANTOS, B. de; NUNES, J. A. Introdução: para ampliar o cânone do reconhecimento, da diferença e da igualdade. In: SOUZA SANTOS, B. de. (Org.). Reconhecer para libertar. Os caminhos do cosmopolitismo multicultural. Rio de Janeiro: Civilização Brasileira, 2003. 